\title{
XI.
}

\section{Ueber Exsudatansammlungen im oberen Paukenraum bei Influenza nebst Bericht über einen operativ geheilten Fall von Sinusthrombose, sowie über zwei interessante Ob- ductionsfälle.}

Von

Dr. Rud. Haug,

Privatdocent in München.

(Von der Redaction übernommen am 1. März 1896.)

\section{Ueber Exsudatansammlungen im oberen Paukenraum bei Influenzaotitis.}

Es ist schon von Kosegarten 1) darauf aufmerksam gemacht worden, dass sich bei Influenza in einer relativ grossen Anzahl von Fällen im Verlaufe einer acuten Influenzaotitis Affectionen des Kuppelraumes bemerkbar machen. Er fand in 97 Fällen 29 mal den Kuppelraum erkrankt und hierunter 25 mal den Atticus allein ergriffen.

Da ich nun an dem Material der verflossenen 5 Jahre sehr ähnliche Beobachtungen gemacht habe, so möchte ich iber die in dieser Beziehung gewonnenen klinischen und theilweise auch anatomischen Resultate referiren.

Es gelangten zur Beobachtung 214 Fälle von Influenzaotitis uberhaupt - als aeute Entziundungen des Mittelohrapparates.

Unter diesen waren 64, bei welchen sich Erscheinungen vorfanden, die auf ein ledigliches Ergriffensein der Pars epitympanica schliessen lassen mussten vermöge des Symptomencomplexes. Aus diesen 64 Fällen sei einer kleinen Anzahl besonders typischer Erkrankungen kurz des Näheren gedacht.

Fall I. Influenzatitis. Hümorrhagisches Exsudat in der vorderen oberen Partie des Trommelfells.

17jähriger Mann seit 10 Stunden an intensiven Ohrschmerzen links leidend. Dabei die Allgemeinerscheinungen einer Influenza der Respirationswege.

1) Zeitschr. f. Ohrenheilk. Bd. XXIII. S. 227.

Archiv f, ohrepheilkande. XI. Ba. 
Ohrbefund: Rechtes Trommelfell normal. Linkes saturirte Röthe der oberen Gehörgangspartie am Uebergange zum Trommelfell; letzteres selbst nach vorn oben in der Shrapnell'schen Region stark bläulich-roth verfärbt und bereits hervorgebuchtet. Processus brev. nicht mehr sichtbar. Injection längs des Hammergriffs, das übrige Trommelfell kaum injicirt, nur leicht hyperämisch glänzend. Hörvermögen mässig herabgesetzt ( $11 / 2$ Meter).

Ordination: Extract. opii 1,0. Acid. carbolici 0,1. Glycerin 10,0. Auf Watte, resp. Gazestreifen eingelegt.

Tags darauf Schmerzen noch viel intensiver, Untere Trommelfellpartie leicht geröthet, aber nicht abgeflacht oder vorgewölbt. Dagegen vorn oben an der Membrana Shrapnelli eine erbsengrosse blasige Hervorbuchtung von bläulich-rother Farbe; die Hervorbuchtung hat eine konische spitz zulaufende Form. Das übrige Trommeltell nicht viel mehr afficirt, als den Tag vorher. Hörweite gleich.

Die sofort vorgenommene Paracentese nach vorn oben zu entleert serosanguinolente Flüssigkeit. In der gleichzeitig behufs bacteriologischer Untersuchung genommenen Portion fanden sich unverkennbar Influenzamikroorganismen.

In der Folge bildete sich kein neues Exsudat mehr, die Schmerzen blieben nach der Entleerung aus.

Heilung am 16. Tage nach Beginn.

Fall II. Acute Influenzaotitis beiderseits; rechts hämorrhagische Media auch der unteren Partien, mit Masloiditis complicirt; links hämorrhagisches Exsudat in der Shrapnell'schen Membran allein.

25 jăhrige Frau seit einem Tage an heftigen beiderseitigen Ohrschmerzen leidend, verbunden mit starkem Sausen und Herabsetzung des Hörens. Es besteht zur Zeit noch allgemeine Influenza der Luftwege.

Rechtes Trommelfell in toto höchstgradig entzündet, in der ganzen unteren Hälfte blauroth verfärbt, vorgebuchtet.

Linkes Trommelfell in der unteren Hälfte stark glänzend, leicht hyperämisch; Hammergriff stark injicirt in der noch sichtbaren unteren Partie. Meatus an der Uebergangspartie zum Trommelfell dunkelroth. Der vordere obere Quadrant nebst Membrana Shrapnelli violettroth, kuglig hervorgetrieben.

Hörweite: Rechts blos laute Sprache in der Năhe des Ohres vernommen. Links Flïstersprache auf 1,75 Meter.

Bezüglich der rechten Seite, als der nicht in diesen speciellen Rayon gehörigen, sei nur bemerkt, dass nach der vorgenommenen Paracentese eine acute eitrige Media sich entwickelte, die - es waren schon vom ersten Tage ab Schmerzen in der Warzengegend vorbanden - sich mit einer gleichzeitigen Erkrankung der Pars mastoidea complicirte, so dass schon am 17. Tage des Verlaufes der Media die operative Eröffnung des Processus vorgenommen werden musste wegen typischen Empyems. Hierauf anstandslose Heilung mit Piestitution des Hörvermögens.

Die uns hier specieller interessirende linke Seite bot am nächsten Tage unter Anhalten und Steigerung der Schmerzen auf der Höhe der bläulichrothen Vortreibung eine gelblichrothe, diffus in die violette Verfärbung übergehende Farbennuancirung dar, die offenbar auf eine Eiterbeimischung hindeutete.

Die nun vorgenommene Discision der oberen Partie ergab auch thatsächlich blutig-eitriges Secret. Nach der Paracentese liessen die Schmerzen zwar nach, verloren sich aber nicht vollständig bis nach 15 Tagen; erst von da ab trat allmăhlich ein Verschwinden der subjectiven Erscheinungen ein. Eine völlige Wiederherstellung war aber erst in der 6 . Woche zu constatiren, da die suljectiven Geräusche, auch nach dem das Hörvermögen in der 4 . Woche auf dieser Seite wieder beinahe normal geworden war, sich erst bis zu diesem Zeitpunkte verloren.

$\mathrm{Zu}$ bemerken wäre bei diesem Falle noch, dass die bacteriologische Untersuchung verschiedene Resultate auf den beiden 
Seiten gab, indem rechts neben dem Influenzabacillus noch Streptokokken sich fanden, während links der Influenzabacillus mit dem Friedländer'schen Pneumococcus constatirt werden konnte.

Fall III. Linksseitige Influenzaotitis mit Vorwölbung der vorderen oberen Partie; spontane Kegelperforation.

48jăhrige Frau seit 6 Tagen an Influenza erkrankt, leidet seit 4 Tagen an starken Ohrschmerzen links mit Schwächung des Hörvermögens und pulsatorischen Geräuschen; seit 3 Tagen Ausfluss aus dem Ohre, der zuerst blutig gewesen sein soll, seit dem letzten Tage eitrig. Die Schmerzen haben nach dem Spontandurchbruch nicht aufgehört.

Die Untersuchung ergiebt das linke Trommelfell in den unteren Partien leicht grauroth ohne Vorwölbung, anch nicht der hinteren Partie. Dagegen zeigt sich die Region der Shrapnell'sehen Membran stark geröthet und vorgetrieben; hart neben dem Processus brevis, der nur unklar, eben angedeutet wahrgenommen werden kann, sieht man eine kleine, spitzkegelige Prominenz, ungefähr wie eine zitzenförmige Granulation sich ausnehmend, an deren nach unten geneigten Spitze ein kleines Eitertröpfchen hängt, nach dessen mechanischer Entfernung sich der lleine Kegel sichtlich balaigst wieder mit Eiter bedeckt.

Hörweite für Flüstersprache auf $90 \mathrm{Cm}$. herabgesetzt.

Da es sich hier offenbar um eine der bekannten sogenannten "Zapfenperforationen" handelte, wurde zunächst die sofortige Discision mittelst geknöpften Messers vorgenommen; allein sie erwies sich, trotzdem sie ausgiebigst bis in den vorderen unteren Quadranten ausgeführt worden war, als nicht genügend, da die Mucosa am 3. Tage nachher wieder genau in der gleichen Weise vorgewuchert war. Es wurde deshalb jetzt mit einem sehr kleinen scharfen Löffel durch die Lücke eingegangen und vorsichtig der innere Trommelfellsaum abgekratzt.

Auf diese Weise gelang es, der eigenthümlichen Granulationsform Herr zu werden. Obschon die Lücke durch dieses Verfahren erheblich vergrössert worden war - in der Folge durch eitrige Einschmelzung des Randes -, heilte der Process, nachdem die Eiterung nach Abschabung der Mucosa in den ersten Tagen an Menge zugenommen hatte, aber schon vom 5 . Tage ab vermindert und vom 16 . Tage ab vollig sistirt war, in der 3 . Woche aus. Fs konnte in der 4. Woche eine reine schöne Narbenbildung vorn oben constatirt werden. Die subjectiven Geräusche aber überdauerten den Schluss der Trommelfelllücke noch volle 6 Wochen; ebenso wie das Hörvermögen erst in der 5 . Woche wieder normal geworden war. Die von der 3 , und 4 . Woche $\mathrm{ab}$ vorgenommenen Lufteinblasungen blieben ohne jeden Effect.

Fall IV. Iofluenzaotitis mit abgegrenztem serösem Exsudate in der Region der Shrapnell'schen Membran.

56 jähriger Maun, bisher immer ohrengesund, erleidet eine Influenzainfection, in deren Verlauf er am 9. Tage über Ohrsymptome linkerseits klagt. Ohne hochgradige Schmerzen stellt sich bei Verminderung des Hörvermögens und gleichzeitigem Sausen ein dumpfes Druckgefühl im Ohre ein.

Als Patient sich 5 Tage nach Beginn der Ohrerscheinungen vorstellte, fand sich das untere Trommelfell beinahe normal, abgesehen von einer leichten Einsenkung. Forn oben, aber nicht ganz bis an die Mitte des Hammergriff's reichend, zeigte sich eine den oberen Quadranten bedeckende flachkugelige Prominenz von der Grösse eines Pfefferkorns, die bei nur minimaler Röthung der oberen Partien des Meatus und Injection der Hammergriffgefässe und leichtester Röthung der bedeckenden Cutisschicht eine exquisit bernsteingelbe Farbe aufwies. In der oberen Partie dieser Vorwölbung zeigte sich das seröse Exsudat - denn um ein solches handelte es sich hier offenbar - scharf contourirt durch eine beinahe gerade verlaufende, nur wenig nach unten ausgebuchtete Linie, die übrigens bei Lageveränderungen des Kopfes sich etwas verschob, der jeweiligen Koptlage entsprechenl.

Hörweite für Flüstersprache auf 2 Meter herabgesetzt. Stimmgabeln 
lateralisiren vom Scheitel nach dem kranken Ohr. Rinne ergiebt aber keine eigentliche Verlängerung der cranio-tympanalen Leitung.

Paracentese der vorgewölbten Partie entleert rein seröse Flüssigkeit.

Obwohl nun nach der Paracentese augenblicklich eine bedeutende Besserung aller Symptome vorhanden gewesen war, blieb diese doch noch nicht von Bestand, da nach Ablauf von 6 Tagen sich das Exsudat wieder erneuert hatte, jedoch ohne dass es zur Eiterbildung gekommen wäre. Eine nochmalige Discision, diesmal ganz im Bogen geführt, verschaffte dauerndes Sistiren der Secretion. Heilung aber erst in der 7 . Woche nach über 14 tägiger Anwendung der Iuftdouche nebst Massage des Trommelfells. (Herstellung des Hörvermögens.) In diesem Zeitpunkte waren auch die subjectiven Geräusche verschwunden.

Fall V. Influenzaotitis mit begrenzlem hümorhagischen Exsudat im hinteren oberen Segmente rechtsseitig, begleitet von starken subjectiven Geräuschen, Schwindelgefühl. Cephalalgie und Supraorbitalneuralgie. Links ebenfalls umschriebenes Lxsudat hämorrhagischen Charakters hinten oben. Paraceulese erst links mit Verschwinden der Erscheinungen, dann auch rechts.

32 jähriger Mann klagt seit 11/2 Tagen über intensive Ohrschmerzen beiderseits, verbunden mit Hörverminderung, starken subjectiven Geräuschen in Form von Brummen und Pulsiren; dazu lebhaftes Schwindelgefühl und Unsicherheit der Körperbewegungen; ausserdem links starke Epiphora, Cephalalgie im Allgemeinen und Supraorbitalneuralgie links.

Von Seite der Respirationsorgane zur Zeit sehr geringe Erscheinungen. Indess sollen die Ohrerscheinungen auf beiden Seiten gleichzeitig nach einem starken Niessanfall aufgetreten sein. Die Untersuchung der Gehörorgane ergiebt rechts eine starke Hyperämie des ganzen Trommelfells bei lebhafter frischer Injection der Hammergriffgefässe, soweit diese nach unten $\mathrm{zu}$ noch sichtbar sind; es ist aber die Membran in der ganzen unteren Hălfte kaum abgeflacht, jedenfalls nicht vorgebaucht.

Im hinteren oberen Quadranten, denselben bis beinahe über die Hälfte nach unten $\mathrm{zu}$ überdachend, sitzt eine kirschkerngrosse schwarzrothe Prominenz, die durch eine nach unten leicht concave Begrenzungslinie abgesetzt erscheint; nach oben spannt sie sich prall, gewissermaassen überhängend, vor. Meatus in der oberen Wand lebhaft dunkelroth.

Linkes Trommelfell ebenfalls ziemlich hyperämisch, aber immer noch wie rechts, unter Erhaltung der sämmtlichen Contourlinien der normalen Attribute, nicht hervorgewölbt, dagegen in den beiden unteren Quadranten zahlreiche frische Ekchymosen als Striche und Punkte. Hinten oben ungefähr die gleiche hämorrhagische Vorwölbung wie rechts, nur noch grösser, praller gespannt und prononcirter.

Die vorderen oberen Quadranten beider Trommelfelle sind frei bis anf die allgemeine Hyperämie.

Hörweite rechts für Flüstersprache $10 \mathrm{Cm}$., links laute Sprache blos vor dem Ohre und da schwer. leitung.

Stimmgabeln vom Scheitel exquisit nach rechts bei verlăngerter Knochen-

Paracentese wird jetzt vorgeschlagen, aber nicht angenommen. Lrst Tags darauf, als die Schmerzen noch viel intensiver aufgetreten waren und sich zu dem schon vorhandenen Schwindelgefühl Sturzbewegungen von rechts nach links gesellten, so dass Patient sich überhaupt nicht mehr erheben oder bewegen konnte, ohne zu Boden zu stürzen, konnte Patient sich mit dem Gedanken der kleinen Operation allmählich befreunden. Dabei hat die Cephalalgie eine ausserordentliche Höhe erreicht; es besteht immerwährend Brechneigung. Die Supraorbitalneuralgie links hat sich mit einer Occipitalneuralgie vergesellschaftet. Ausserdem noch beftiger Blepharospasmus links. Puls 112. Temperatur $39,4^{\circ}$.

Unter diesen Bedingungen wird endlich am nächsten Tage die Paracentese gestattet und zunächst die breite Eröffnung des Exsudatsackes der linken Seite vorgenommen.

Das Resultat war ein frappirendes, indem die sămmtlichen allarmirenden 
Erscheinungen in Zeit von wenigen Stunden völlig weggewischt waren, ebenso auch der Schmerz der linken Seite; die Hörweite betrug gleich nach der Paracentese 2,4 Meter für Flüstersprache.

$\mathrm{Da}$ die Schmerzen rechts noch nicht viel besser geworden waren, wurde am nächsten Tage auch die Paracentese des anderen Trommelfells sogar vom Patienten verlangt, nachdem er sich vom Erfolge überzeugt hatte. In der Folge stellte sich auf keinem Obre eine Eiterung ein. Am 10. Tage nach Beginn der Erscheinungen war das Trommelfell beiderseits völlig abgeblasst, die Schnittöfinung verheilt, das Hörvermögen beiderseits sehr bedeutend gebessert. Am 19. Tage beiderseits Restitutio ad integrum.

$\mathrm{Zu}$ bemerken ist noch, dass das beiderseits steril aufgefangene bämorrhagische Exsudat im Wesentlichen beinahe nur Influenzamikroorganismen enthielt.

Fall VI. Influenzaotitis links mit Vorwolbung der hinteren oberen Partie (eitrig-hämorrhagisches Exsudat); starke Algemeinerscheinungen; Paracentese; Senkung der hinteren Gehörgangswand; Mastoiditis.

17 jäbriges Mädchen hat vor 4 Tagen zuerst Angina gehabt, mit der gleichzeitig die Erscheinungen des Ohrenzwangs linkerseits, der der afficirten Halsregion entsprechenden Seite, auftraten. Seit 2 Tagen hat sich der Ohrdruck zu einer sehr hochgradigen Schmerzhaftigkeit gesteigert, verbunden mit starker Schwerhörigkeit, intensiven subjectiven Geräuschen und ausgesprochenem Schwindelgefühl. Seit dem letzten Tage auch Schmerzen in der Warzenfortsatzgegend. Allgemein bestehen noch dabei die Symptome eines Influenzaanfalles.

Die Untersuchung am Beginn des 5. Tages ergiebt am linken Gehörorgan eine intensive Röthung und Schwellung der Gehörgangspartien im Uebergange zum Annulus, speciell die hintere und obere Wand ganz dunkelroth. Im hinteren oberen Segmente sitzt eine, den hinteren oberen Quadranten bis zu drei Viertheilen einnehmende Vorwölbung von Erbsengrösse. Ihre Farbe ist auf der Höhe und nach unten zu grauröthlichgelb, oben violett; die ganze Exsudatpartie ist nach unten ziemlich scharf abgegrenzt durch eine Bogenliuie, die dem Exsudatsack den Anblick des Ueberhängens giebt; nach unten liegt ein deutlicher Schlagschatten. Das ganze übrige Trommelfell weist, besonders in der unteren Hălfte, mit Ausnahme einer mittelgradigen Hyperämie, keine Zeichen von Exsudation auf; es ist nicht abgeflacht oder vorgewölbt.

Hörvermögen, vorher normal, sehr schlecht; Flüstersprache überhaupt nicht verstanden. Stimmgabeln nur ins linke $\mathrm{Ohr}$ bei sehr verstärkter Knochenund verkturzter Luftleitung.

Warzenfortsatzgegend spontan und auf Druck ziemlich empfindlich:

Die sofort vorgenommene Paracentese des hinteren oberen Segmentes entleert eine verhältnissmässig nicht geringe Menge blutig-eitrigen Secretes (bacteriologisch Influenzabacillen neben Streptokokken). Es werden hierauf zwar in den nächsten Tagen die Symptome milder, insbesondere verliert sich der Schwindel, doch tritt keine völlige Rückbildung in Kürze ein. Im Gegentheil wird die Schmerzhaftigkeit der Regio mastoidea immer stärker ausgeprägt, begleitet von intensiven Kopfschmerzen der betroffenen Seite; insbesondere gegen Abend exacerbiren diese Kopfschmerzen unter gleichzeitiger Erhöhung der Temperatur.

Trotz wiederholter Eröffnung des oberen Segmentes und - vorsichtshalber - auch der unteren Hälfte des Trommelfells, wobei sich aber, wie vorauszusehen war, nicht eine Spur von Seeret entleerte, stellt sich bei reichlichem Ausfluss von Fiter aus der oberen - nicht der unteren, nach zwei Tagen wieder verheilten - Oeffinung eine hochgradig schnell sich entwickelnde Senkung der hinteren oberen Gehörgangswand ein. Die Warzenfortsatzgegend ist nun auf Druck ausserordentlich empfindlich sowohl an der Spitze, als kurz unterhalb der Linea temporalis, ebenso dauern die Spontanschmerzen unter năchtlichen Exacerbationen fort. Dabei fehlt jede Schwellung der Weichtheile, jede Röthung. Bei der Percussion lässt sich eine ganz prägnante deutliche Abdämpfung im Vergleich zur gesunden Seite eruiren.

Es war somit, am 17. Tage der Erkrankung, kein Zweifel mehr möglich, dass die Hohlräume der Pars mastoidea in Mitleidenschaft gezogen seien. 
Der operative Eingriff wurde deshalb sofort vorgenommen und er ergab die vollige Richtigkeit der Annahme: Corticalis ganz gesund; in $0,8 \mathrm{Cm}$. Tiefe wird das Antrum eröffuet (erbsengross), es enthält reinen gelben Eiter, ebenso wie die Spitzenzelle, die hier sehr stark entwickelt ist. Die Wandungen des Antrum erweisen sich trotz der Kürze der Zeit schon ziemlich rauh. Unmittelbar auf diesen Eingxiff hin verschwanden sämmtliche Allgemein- und Localerscheinungen und bereits am 12. Tage nachher war die Secretion sowohl aus dem Ohre wie aus der Warzenfortsatzwunde erloschen.

Im Beginn der 5. Woche - nach der Operation - völlige Ausheilung mit absoluter Rückbildang der Hörverminderung.

Fall VII. Influenzaotitis rechts. Hämorrhagisch-eitriges Exsudat hinten oben. Nach der Paracentese dauern die von Beyinn an dagewesenen Schmerzen der Regio mastoides noch 6 Tage fort, um dann zu versohwinden.

65 jähriger Mann, bisher ohrengesund wie die Personen der bisher beschriebenen Fälle, ist seit 5 Tagen an katarrhalischer Influenza erkrankt. Schon am 2. Tage der Erkrankung Ohrschmerzen rechterseits, die an Intensitat immer mehr zunehmen und sich mit rapider Abnahme des Hörvermögens unter Begleitung subjectiver Geräusche combinirte. Intensiver halbseitiger Kopfschmerz, sowie ausstrahlende Schmerzen bis gegen das Sternum. Schmerzhaftigkeit der Warzenfortsatzgegend besteht seit 2 Tagen.

Die Untersuchung des Ohres ergiebt eine starke Röthung des Trommelfells in allen Theilen, in der unteren Partie und vorn oben, aber ohne nachweisbare Vorwölbung. Die hintere obere Partie aber ist eingenommen von einer vom Hammergriff bis an den hinteren Limbussaum reichenden, nach unten scharf abgesetzten, ungefähr dreieckigen Vorwölbung. Die Farbe dieser Prominenz ist ein schmutziges Gelbroth nach oben $\mathrm{zu}$ mit lividem Farbenton.

Der ganze umgebende knöcherne Meatus stark gerïthet. Warzenfortsatz auf Druck und Klopfen schon recht empfindlich an den typischen Stellen, ebenso auch spontan. Röthung und Schwellung fehlen. Eine Abdämpfung des Percussionsschalles ist jedoch nachzuweisen.

Hörweite für Flüstersprache ganz aufgehoben. Stimmgabeln in das kranke Ohr bei völlig aufgehobener Luftleitung und nicht verlängerter Knochenleitung.

Die sofort vorgenommene Paracentese am Orte der Wabl, von oben bis nach hinten unten - obschon hier keine Vorwölbung mehr war - entwickeit reichliches blutig-eitriges Exsudat, das bei der mikroskopischen Untersuchung zahlreiche specifische Mikroorganismen aufweist.

Auf diesen Eingrifi hin besserten sich die Erscheinungen insbesondere bezüglich der Schmerzen; es entwickelt sich aber eine mit sehr starker Secretion einhergehende eitrige Media. Die Schmerzen in der Regio mastoidea danerten noch 6 Tage an, von da ab blieben sie dauernd weg. Eigenthümlich war und blieb während der ganzen Dauer der Eiterung, dass das untere Ende der Paracentesenöffnung trotz wiederholter Dilatation sich immer wieder rasch schloss und der Eiter immer aus der Lücke im hinteren oberen Quadranten abfloss. Die in der späteren Zeit des Verlaufes vorgenommene Luftdouche brachte kein Perforationsgeräusch zu Tage; es war iiberhaupt kein Einfluss auf den Process von ihr wahrzunehmen

Die Heilung erfolgte in der 9. Woche, bis zu diesem Zeitpunkte war die Secretion erloschen und das Trommelfell verheilt mit einer nach hinten oben zu fest adhärenten Narbe, die den weiteren Mobilisationsversuchen einen ziemlich erfolgreichen Widerstand entgegensetzte, indem sich blos die vordere untere Partie derselben lockern liess. Die Folge davon war, dass das Hörvermögen immerhin ziemlich geschwăcht blieb, $90 \mathrm{Cm}$. für Flüstersprache; ebenso verschwanden auch die subjectiven Geräusche nicht mehr völig.

Fall VIII. Influenzaotitis purutenta links nit Spoutandurchbruch; Schmerzen in der Mastoidgegend von Beginn an; starke Begleiterscheinungen meningealer Natur; kegelförmige granulirte Prominenz hinten oben. Mastoiditis. Sinusthrombose. Operation. Heilung.

33 jähriger Mann, vor über 4 Wochen, nach Angabe des behandelnden Arztes zunächst an Influenza - die bacteriologisch im pneumonischen Sputum 
nachgewiesen worden sei - erkrankt, hat seit 24 Tagen Otorrboe links, die sich nach 3 tägigen Schmerzen eingestellt habe. Schmerzen in der Warzenfortsatzgegend seien gleich innerhalb der allerersten Zeit aufgetreten und seit 6 Tagen habe sich auch leichte Schwellung und Röthung der Warzenfortsatzgegend noch dazugesellt. Es bestehen immer starke Kopfschmerzen, besonders der linken Seite, dazu seit 4 Tagen Antälle von Schwindel. Subjective Geräusche fehlen. Seit $1^{1 / 2}$ Tagen besteht eine dem Arzte auffällige, im Contrast zu den früheren lebhaften Schmerzensäusserungen stehende Indolenz neben sich steigernder Schlafsucht. Dabel ist die Temperatur Abends hoch, 38,9 bis $39,6^{\circ}$. Puls $68-56$. Seit 4 Tagen ist der vorher rein eitrige und sehr reichliche Austluss an Menge geringer geworden und blutig-eitrig, ohne jedoch Fötor aufzuweisen.

Die Untersuchung (16. März 1895) des erkrankten Ohres ergiebt zunächst schon eine beträchtliche Senkung der hinteren oberen Gehörgangswand. Das Trommelfell nach Entfernung des blutig-eitrigen Exsudates und massenhafter Epithelfetzen trüb grauroth. Im binteren oberen Quadranten eine kleinkirschkerngrosse graurothe Prominenz von Kegelform, auf deren Höhe zwei oder drei grieskorngrosse gelblichrothe Granulationsknöpfchen lagern. Es sind dies aus dem Kegelkrater herworlugende Granulationen, zwischen welchen der Eiter immer wieder von Neuem hervorquillt. Eine durch die Perforation eingeführte Sonde gelangt - ohne jede Gewalt - nach oben und löst sofort eine heftige Sturzbewegung aus.

Die Pars mastoidea ist in der Hautdecke leicht infiltrirt und kaum geröthet, aber auf Druck an der Spitze und oben äusserst empfindlich. Percutorisch ist Abdämpfung nachweisbar. Hörfähigkeit für Flüstersprache (scharf) auf $10 \mathrm{Cm}$. herabgesetzt. Stimmgabelversuche lassen sich bei dem Zustande des Patienten nicht ausführea.

Es werden nun zunächst mittelst kleinen scharfen Löffels die Granulationen von innen nach aussen abgetragen und die Oeffnung mit dem doppelschneidigen geknöpften Messer gehörig dilatirt, auch nach unten bis an den Limbus.

Hierauf wird die Secretion wieder sehr reichlich unter Nachlass der Schmerzen und bedeutender Besserung der Allgemeinerscheinungen. Jedoch nach 5 Tagen - die untere Oeffnung hatte sich, da sie offenbar mit dem Eiterherde nicht in Verbindung stand, schon wieder geschlossen - war genau wieder das gleiche Symptomenbild vorhanden und die Senkung der hinteren oberen Meatuswand war so hochgradig, dass ich die weitere Behandlung hätte ablehnen müssen, wenn nicht in den schon erstmals vorgeschlagenen operativen Eingriff gewilligt worden wäre.

Dazu bestimuten mich, ganz abgesehen von den vorliegenden Localverhältnissen, das acute und verstärkte Auftreten von bedrohlichen Allgemeinerscheinungen, speciell eines ausgesprochenen und eines angedenteten Schüttelfrostes mit consecutiver Temperatursteigerung auf $39,8-40,2^{\circ}$. Puls 56-52. Schwellung in der Temporalgegend $u, s$. w bestand nicht, aber ausserordentliche Percussionsempfindlichkeit etwas uber der Linea temporalis, ungefähr in etwa $3 \mathrm{Cm}$. Längenausdehnung bei sehr geringer Breite des Percussionsschmerzes - soweit es sich bei dem wieder sehr indolent gewordenen Patienten feststellen liess. Die Schwellung der Pars mastoidea war geringer geworden, so dass hier beinahe nichts mehr dayon nachzuweissen war. Dagegen war die Schmerzhaftigkeit spontan und auf Druck beinahe noch stärker wie vorher. Brechen und Brechneigung nicht vorhanden. Im Warzenfortsatzwinkel ist der Druck nach unten zu, längs des Sternocleidomastoideus, schon sehr empfindlich. Strangartige Verhärtung jedoch nicht in der Tiefe nachweisbar, ebenso wie keine Drüsenschwellungen deutlich nachgewiesen werden können. Eine vermehrte Resistenz scheint jedoch da zu sein. Es stellt sich Irrereden im Coma ein. (Status vom 21. März 1895.)

Die ophthalmoskopische Untersuchung ergab eine ausgesprochene Neuroretinitis optica links. Papillenränder stark verwaschen, Venen sehr geschlängelt und pulsirend, zudem radiäre Streifung. Rechts fand sich blos leichteres Verwaschensein des inneren Papillenrandes.

Es war unter diesen Verhältnissen wohl zweifellos, dass septisches 
Material bereits in die Blutbahnen eingebrochen war und dass eine intracranielle Complication ausser der Mastoiditis vorlag.

O peration (22. Márz 1895). Hautschnitt wie bei der Radicaloperation bis an die Temporalregion; hierauf noch ein Dilatationsschnitt, senkrecht auf die obere Partie des Warzentheilsschnittes. Weichtheile beinahe nicht geschwollen, werden sammt der abgelösten Gehörgangswand zurückgelegt. Periost derb. Corticalis gesund. Warzenfortsatz kurz amputirt mit grossem $(1,2 \mathrm{Cm}$. breiten) Hohlmeissel von oben nach unten. Antrum und Spitzenzelle - blos die zwei sind vorhanden - mit gut gelbem Eiter gefüllt. Gerade in dem hinteren oberen Winkel der mit dem scharfen Löffel und Meissel ausgearbeiteten Knochenhöhle macht sich ein thrombosirtes Emissar bemerbkar. Wandungen nirgends raub. Wegnahme der hinteren und oberen Wand des Warzentheils successive langsam, bis Dura und Sinus in Markstückgrösse freiliegen. Dura ausserordentlich hyperămisch, aber nirgends missfarbig, ebenso keine Granulationen, wie überhaupt auch in den primären Höhlen keinerlei solche $\mathrm{zu}$ sehen gewesen waren.

Der Sinus liegt an einer ca. $14 \mathrm{Mm}$. breiten, beinahe in der Mitte gelegenen Stelle dellig eingebuchtet, völlig pulslos und wenig collabirt da, an den peripheren, hart angrenzenden Partien derb sich anfühlend. Die Punction dieser centralen Partie ergab blutig gefärbten Eiter.

Es wurde nun die Sinuswand der Lănge nach incidirt, ohne jede Blutung. Der Sinus erwies sich in der bisher freigelegten Strecke obturirt durch einen rothbraunen Thrombus, der in der Mitte stark puriform erweicht war. Da aber mit dieser Freilegung offenbar noch nicht die beiden Enden des Thrombus freigelegt waren, wurde der Knochen nach hinten und vorn noch weiter abgetragen. Vorn war die Grenze schon nach $0,3 \mathrm{Cm}$. erreicht: hier war der Sinus wieder bluthaltig, nach hinten musste aber die Knochendecke noch um über $1 / 2 \mathrm{Cm}$. abgetragen werden, bis sich, aber sehr knapp vor der Grenze, wieder freier Sinus vermuthen liess.

Der braunrothe Thrombus wurde vorsichtig bis kaum etwa der Hälfte gegen die Peripherie zu ausgeräumt. Die nun aber $2,0 \mathrm{Cm}$. in der Länge betragende Höle im Sinus warde einfach tamponirt. Der Erfolg des Eingriffes war ein voller in jeder Beziehung. Obschon ich gefurchtet hatte, dass vermöge der bereits ja in leichtem Grade wohl schon vorhanden gewesenen Affection der Jugularis anch an dieser die ja lege artis eigentlich vorauszuschickende Unterbindung noch schliesslich vorgenommen werden müsste, erwies sich diese Befürchtung in der Folge als unnöthige.

Ohne Wiederholung eines Schüttelfrostes verlief die Erkrankung, dass am Tage nach der Operation Abends blos $37,8^{\circ}$ zu constatiren war. Dabei innerhalb 24 Stunden ein völliges Neuaufleben mit Verschwinden der comatösen Erscheinungen. Puls 82. Temperatur in den nächsten 6 Tagen Morgens $36,8-36,4$, Abends $37,8-37,0$ (bis zum dritten Verbandwechsel).

Veränderungen im Augenhintergrund weg bis auf eine minimale Schlängelung der Venen links; Papille beiderseits normal, links noch einen leichten Schlagschatten nach innen $z u$ aufweisend, der aber noch uber 8 Tage lang constatirt werden konnte.

Heilung in der 9. Woche. Trommelfell vernarbt mit einer etwa hanfkorngrossen Narbe an der hinteren oberen Partie. Die Secretion hatte schon am 10. Tage sistirt (aus dem Ohre). Hörfähigkeit für Flüstersprache 2,8 Meter. $\mathrm{Es}$ besteht tief gestimmtes Sausen fort. (Status rom 12. Juni 1895.)

Fall IX. Influenzaotitis mit Exsudat (eitrig-blutig) hinten oben. Zapfenperforation.

26 jährige Frau, bisher ohrengesund; vor 12 Tagen Influenzaanfall; seit 4 Tagen Ohrschmerzen rechts mit Hörverschlechterung und subjectiven Geräuschen. Erhebliche Kopfschmerzen der rechten Seite combinirt mit neuralgischen Schmerzen bis ins Occiput ausstrahlend. Schmerzen in der Warzenfortsatzgegend seit 1 Tage.

Untersuchung am 4. Tage ergiebt das rechte Trommelfell in toto stark geröthet, ebenso die angrenzenden Gehörgangspartien. Hammergriff und Proc. brevis noch als gelbliche Linie bez. Punkt sichtbar; das sonst eben kaum 
abgeflachte Trommelfell weist eine gerade den hinteren oberen Quadranten einnehmende gut linsengrosse pralle Vorbuchtung auf, die sich uber den Limbus nach oben geradezu herauszwängt, zugleich erscheint die obere Gehörgangswand gesenkt. Die Farbe der Vorwölbung ist ein schmutziges Violett mit grünlich gelbem Tone gemischt. Processus an der Spitze mässig empfindlich, dagegen oben an der Basis sebr empfindlich auf Druck, jedoch keine Röthung und Schwellung.

Hörweite für Flüstersprache aufgehoben.

Discision des Sackes allein, ohne auf das übrige Trommelfell einzudringen, entleert blutig eitriges Secret. Die Schmerzen lassen hierauf nach, ebenso verschwindet die Schmerzhaftigkeit am Warzenfortsatz. Hörfähigkeit jedoch bessert sich nun sehr wenig. Secretion durch 3 Wochen sehr stark, rein eitrig, immer blos von oben her kommend trotz Dilatation nach unten. Luftdouche im Anfange der 3. Woche angewandt giebt kein charakteristisches Perforationsgeräusch.

Am Ende der 3. Woche zeigt sich ein banfkorngrosses, zapfenförmiges Granulationsknöpfchen, ungefähr der Lage der Mitte der hinteren Falte entsprechend, das auf Chromsäureätzung dauernd verschwindet. Sistirung der Secretion im Beginne der 5. Woche. Narbe hinten oben in der 6 . Woche nachzuweisen.

Das Hörvermögen hat sich bei Luftdouche und Massage des Trommelfells langsam gebessert, ist aber erst im 3. Monate wieder annähernd gut geworden (Flüstersprache 7,4 Meter). Die subjectiven Geräusche dauerten bis zu 5 Monaten fort, um erst von da ab dauernd zu verschwinden.

Eigenthümlich ist, dass das Trommelfell seit der Vernarbung völlig unempfindlich geworden ist und blieb; stärkere Insulte, wie directes derbes Auftupfen mit der Sonde wird nicht empfunden im ganzen Rayon, obwohl sofort eine consecutive Hyperämie folgt.

Fall X. Beiderseits seroses Exsudat infolge von Influenzakatarrh. Geringe Schmerzen, dagegen starkes Schwindel- und Sturzgefüht; Linls Exsudat im Gebiete beinahe des ganzen Trommelfells; rechts Exsudat blos hinten oben. Paracentese der linken Seite hat keinen Einfluss auf die Sturzbewegungen, dagegen hebt die später vorgenommene der rechten Seite sie auf.

45 jähriger Mann, vor 10 Tagen mit Influenza erkrankt, seit 9 Tagen anf beiden Seiten schwerhörig - vorher nie ohrenkrank - klagt über dumpfen Druck in beiden Ohren und starkes Sausen ohne eigentliche Schmerzen. Dagegen besteht seit 4 Tagen immer mehr zunehmendes Schwindelgefühl, abwechselnd mit Sturzgefühl, so dass Patient die willkürliche Herrschaft über seine Bewegung zum grossen Theile verloren hat.

Bei der am 10. Tage der Ohrerkrankung vorgenommenen Untersuchung fallt es zunächst auf, dass Patient kaum im Stande ist, gerade zu gehen, er schwankt, besonders von rechts nach links; bei geschlossenen Augen geht die Directive völlig verloren und er droht zu stürzen. Die Gegenstände bewegen sich vor seinen Augen nach links zu.

Hörweite für Flüstersprache links ganz aufgehoben, rechts $10 \mathrm{Cm}$. Stimmgabeln werden sämmtlich nach rechts verlegt bei nicht sehr verlängerter Knochenleitung.

Trommelfelle: links mässig geröthet, aber in der ganzen unteren Hälfte und noch in der hinten oberen Partie stark vorgebaucht und bernsteingelb verfärbt. Es zieht sich eine dentlich sichtbare scharf contourirte Exsudatlinie von der Höhe des vorderen unteren Quadranten schief aufwärtssteigend nach hinten oben bis über die Mitte des hinteren oberen Segmentes. Bei Neigung des Kopfes lässt sich eine deutliche Verschiebung der Exsudatgrenzen erkennen.

Rechts: Trommelfell ebenfalls mässig roth, aber in den unteren Partien nicht vorgewölbt. Dagegen ist der ganze Winkel hinten oben von etwa der Mitte des Hammergriffs bis an den Saum eingenommen durch eine nach unten ziemlich scharf abschliessende, prall gespannte Vorwölbung, die die nämliche Farbe aufweist, wie die linke Seite. Eine eigentliche Exsudatlinie lässt sich hier jedoch nirgends sehen. Von hinten und oben her hängt der Sack über den Limbus heraus. 
Es wird nun die Paracentese vorgenommen, und zwar zunächst nur auf einer Seite, um zu erkennen, von welchem Ohre aus wohl die Schwindelerscheinungen ausgelöst worden seien.

Die Paracentese des linken, als des in höherem Grade betheiligt erscheinenden Trommelfells entwickelt eine verhaltnissmässig grosse Menge beinahe rein serösen Exsudates. Hörfảhigkeit sofort nach Abfluss des Secrets 3,4 Meter.

Auf dem rechten Ohre wird unterdessen bis zur nächsten Consultation, am übernächsten Tage, Carbolglycerin 10 Proc. eingeträufelt. Es ergab sich nun, dass die Discision des linken Trommelfells beinahe gar keinen Eintluss gehabt hatte auf die in Frage stehenden Erscheinungen; sie waren so ziemlich gleich geblieben, wenn auch kaum stärker geworden.

Dagegen war die am linken Ohre, also 2 Tage nachher vorgenommene Paracencese von vollem Erfolg begleitet.

Sofort nach Entleerung des Exsudatsackes war nicht nur das Hörvermögen wesentlich gebessert, sondern Patient erklärte aus freiem Antriebe nach einigen Bewegungsversuchen freudigst, jetzt könne er wenigstens wieder gerade gehen. Thatsächlich ergab sich auch, dass selbst bei geschlossenen Augen reguläre Gehbewegungen ausgefuhrt werden konnten, dass absolut kein Schwanken mehr vorhanden war, während vorber noch das Rhomberg'sche Phänomen ganz gut gelungen war.

Der Verlauf dieser beiden Exsudatansammlungen war weiterhin ein günstiger, indem sich keine weitere Secretion einstellte, das Hörvermögen sich vermöge der nun bald vorgenommenen Luftdouche wieder zur Norm zurückbildete. Links blieben die Geräusche yon der Paracentese ab weg, rechts jedoch dauerten sie noch bis in die 5. Woche, um sich von da ab auch, aber nur allmählich, ganz zu verlieren.

Fall XI. Obduction eines an intercurrenter Lirrankung gestorbenen Falles. Eiteransammlung im Recessus epitympanicus, in der Hammer-Ambossnische, im Prussak'schen Raume, der nitch unten durch Vcrlöthungen abgeschlossenen hinteren Trommelfelltasche, Vorwolbung des Trommelfells hinten oben. Eiter im Aditus ad antrum, Antrum und der Spitzenzelle.

48 jähriger Mann, der früher an katarrhalischer, aber nicht eitriger Media gelitten baben soll, war vor 9 Tagen an Influenza erkrankt und am 10. Tage an Influenzapnermonie gestorben. Am Tage vor dem Exitus letalis war ich wegen nicht mehr genau vom Patienten anzugebenden Ohrensymptomen gerufen worden; angeblich bestanden Obrschmerzen erst seit 2 Tagen, ebenso Abnahme des Hörvermögens.

Schmerzen in der Warzenfortsatzgegend sollen ebenfalls von Anfang an gleichzeitig vorhanden gewesen sein. Als ich den Patienten, 12 Stunden vor seinem Tode, untersuchte, fand ich rechts die obere und theilweise auch die hintere Partie des Gehörgangs intensiv geröthet und leicht geschwollen, jedenfalls beginnende Senkung der hinteren Wand.

Das Trommelfell selbst tief dunkelroth, jedoch Hammergriff noch eben angedeutet. In der unteren Hälfte war keine Vorwölbung vorhanden, aber die ganze hintere obere Partie war in Form einer circumscripten buckligen, erbsengrossen Prominenz vorgebaucht. Ihre Farbe ist ein fahles Dunkelrothgelb. Auch die vordere obere Partie ist, allerdings nur leichter, vorgewölbt.

Warzenfortsatz auf Iruck anscheinend, soweit es sich bei dem bereits mit starken Herzerscheinungen kämpfenden Patienten nachweisen liess, sehr emptindlich, jedoch keine Spur einer Schwellung. Percutorisch ist eine Schallabdämpfung nachzuweisen.

Das linke Ohr ist normal.

Die sofort vorgenommene Paracentese entwickelt blutig eitriges Exsudat, hat jedoch auf den weiteren Verlauf keinen Einfluss mehr; ein tieferer Bingriff wurde abgelehnt und wäre anch bei dem schon moribunden Patienten ohne Frfolg gewesen.

Section: 10 Stunden nach dem Tode ergiebt zunächst eine Pleuritis exsudativa dextra hämorrhagica und Pneumonie beider Ober- und des rechten Unterlappens als directe Todesursache.

An dem vorliegenden rechten Gehörorgane sieht man zunächst das in 
allen Theilen geschwollene Trommelfell durch eine von hinten oben, kurz nach dem Processus brevis beginnende bis in den vorderen unteren Quadranten verlaufende bogenförmige Schnittlinie zertheilt; die untere Hälfte der Wunde erscheint bereits verharscht, aus der oberen sickert blutig-eitriges Fluidum hervor.

Die untere Partie des Paukenhöhlenranmes weist abgesehen von einer mässigen Hyperämie keinerlei besondere Veränderungen auf. Dagegen sehen wir im oberen Paukenraume die Hammer-Ambossnische mit blutig-eitrigem Exsudate gefullt, ebenso den Prussak'schen Raum und die hintere Trommelfelltasche, die nach unten zu mit dem Trommelfelle grossentheils verwachsen ist durch offenbar ältere membranöse Adhäsionen von sehr derber Consistenz. Dieser abgeschlossene Raum seinerseits ist wieder durch pathologische Ligamente in zwei separate Hohlräume getheilt. Der Prussak'sche Raum und die hintere Tasche communiciren durch eine jedenfalls präformirte Lücke in der Wand des Prussak'schen Raumes. Ebenso zeigt die nach dem Paukenraume zu freie Seite der Tasche einen präformirten ovalen Schlitz, durch den das Exsudat von hinten oben her in Verbindung tritt. Zudem sehen wir noch die Steigbuigelplatte gelockert, ihre Umgebung entzündlich infiltrirt und die Fenstermembran selbst imbibirt, central und lateral nach hinten erweicht und im Ganzen stark nach einwärts gebuchtet. Es ist Exsudat durch die an der medialen Seite geluftete und leicht abstehende Platte eingedrungen. Die Möglichkeit hierzu war gegeben durch eine primăre Lockerung und entzündliche Schwellung $z$ wischen dem Steigbägelköpfichen und dem Ossiculum lenticulare.

Im ganzen hinteren Recessus weiter und im Aditus ad antrum und im Antrum mastoideum selbst findet sich bereits das gleiche blutig-eitrige Exsudat, während die hier nicht schlecht entwickelten übrigen Hohlräume sammt der ziemlich grossen Spitzenzelle lediglich die Zeichen einer hochgradigen Hyperämisirung aufweisen. Im inneren Ohre findet sich nichts Besonderes, ausgenommen ein Vordringen der eitrigen Infiltration in der nächsten Umgebung des ovalen Fensters.

Fall XII. Obduction eines intercurrent gestorbenen Falles. Seroses Exsudat hauptsüchlich in dem hinteren Theile des Recessus, das sich durch die nach unten durch frische membranöse Adhusionen geschlossene hintere Tasche in das Trommelfell ergossen hatte und nach Einreissung der Mucosa und Propria die Cutis linten oben in Form einer grossen Exsudatblase ausgebuchtet hatte.

27 jährige Frau, war am 16. Tage nach einer Influenzapneumonie ge: storben. 10 Tage vor dem Tode hatte sie über geringe Schmerzen im rechten Ohre geklagt, die von erheblicher Schwerhörigkeit gefolgt gewesen waren. Ausfluss sei aie vorhanden gewesen.

Eine Untersuchung des Ohres intra vitam war von dem behandelnden Arzte "wegen der geringen bald wieder verschwundenen Schmerzen" nicht vorgenommen worden.

Schwindel sei vorhanden gewesen, wurde aber mit anderen Organerkrankungen in Zusammenhang gebracht.

Das herausgenommene rechte Schläfenbein weist auf: Trommelfell bei der Besichtigung von vorne her erhalten, zeigt geringe Symtome von Entzündung. Hinten oben, beinabe bis zur Mitte des hinteren oberen Quadranten reichend eine blasige Vorbuchtung mit durchscheinend gelber Verfärbung. Vorn oben an der Shrapnell'schen Membran ist eine leichtere ebenfalls gelblich verfärbte Vorwölbung zu sehen; aber in der unteren Halfte des Trommelfells nichts.

Nach präparatorischer Wegnahme des Paukendaches, das ausserordentlich dünn, durchscheinend ist, sieht man die ganze hintere und obere Partie mit Einschluss der Steigbügelregion ausgefüllt von einer dünnen Flässigkeit. Insbesondere erscheint die hintere Taschenfalte stark ausgebuchtet. Die vorhin beschriebene blasige Vorwölbung beruht jedoch lediglich auf einer umschriebenen Ansammlung von seröser Flüssigkeit zwischen der Cutisschicht einerseits and der Propria-Mucosa andererseits. Es besteht aber eine Communication zwischen der hinteren Tasche und dem Exsudatbeutel, indem die innerste Trommelfelllamelle sich schlitzförmig eingerissen zeigt und die Tasche nach unten zu durch membranöse Verlöthungen abgeschlossen erscheint, so 
dass also das in der Tasche angesammelte Exsudat nach Durchreissung der erweichten Mucosa und Propria nach vorne dringen und die Cutis beutelformig vorstulpen konnte.

Auch der Prussak"sche Raum and die Hammerambosbucht sind mit dem Exsudat angefullt, so dass dasselbe sich gegen die Shrapnell'sche Membran zu senkt und sich theilweise noch in sie ergiesst.

Der untere Theil des Paukenraumes erscheint frei, die Schleimhaut so gar eher blass.

Im Warzentheil ist kein Exsudat zu finden. Labyrinth erweist sich im ganzen frei, doch scheint die Verschlussplatte des ovalen Fensters gequollen, wie imbibirt.

Epikritische Betrachtungen.

Ich habe aus der Gesammtbeobachtungszahl von 64 hierhergehörigen Fällen blos diese 10 klinischen und die 2 Sectionsberichte ausgezogen, weil sie diesen specieller zu erörternden Typus der Localerkrankung gut repräsentiren.

Was zunächst die klinische Seite der Erkrankung anlangt, so geht aus allen Beobachtungen bervor, dass lediglich der obere Paukenabschnitt der allein afficirte gewesen ist; in fast allen bierhergehörigen Fällen fand sich die untere Trommelhöhlenpartie entweder gar nicht mitbetheiligt, was das Häufigere war, oder sie war nur in ganz nebensächlichem untergeordneten Maasse mitafficirt.

Wir werden wohl zu unterscheiden haben zwischen den Exsudatansammlungen in der vorderen, die Shrapnell'sche Region mit einbegreifenden Partien und solchen der hinteren Partien. Daneben giebt es immer noch eine Anzahl von Fällen, in denen die gesammten oberen Stockwerke des Trommelhöhlenra u m es gleichzeitig erkrankt sind.

Dass bei sämmtlichen beschriebenen Fällen wirklich Influenza die Ursache der Ohrentzündung gewesen ist, geht theils aus dem specifischen klinischen Verhalten, theils aus dem directen bacteriologischen Nachweis der Bacillen entweder im Ohrsecrete oder in anderen Körperorganen hervor.

Zunächst lassen sich die circumscripten Exsudationen nach vorn zu kennzeichnen dadurch, dass zumeist im Gebiete der Shrapnell'schen Membran allein eine umschriebene Vorwölbung erfolgte in dem die Influenza eigenen acuten Typus unter Bildung von hämorrhagischem Exsudate, eventuell unter Beimischang von Eiter. Die subjectiven Erscheinungen des Schmerzes erreichten eine grosse Intensität, erlangten jedoch nicht die Höhe wie sie bei allgemeiner Influenzatympanitis häufig angetroffen werden. Die vordere und obere Gebörgangswandung ist in diesen Fällen beinahe constant stark geröthet und tritt in späteren Stadien zuweilen herab. Bei der einfach exsudativen, nicht hämorrhagisch 
oder hämorrhagisch-eitrigen Form waren die subjectiven Erscheinungen gewöhnlich als sogar verhältnissmässig geringfügige zu bezeichnen.

Die Herabminderung des Hörvermögens war in fast allen nach vorn oben zu localisirten Fällen eine nicht sehr hochgradige, indem die Fliistersprache meist noch auf 1 Meter und oft weit darỉber exact vernommen wurde. Dagegen waren die Ohrgeräusche anch hier schon in ziemlich quälender Form ausgesprochen.

Der Verlauf war bei frühzeitig genug vorgenommener Paracentese ein im Allgemeinen ginstiger, indem die Schmerzen nachliessen und es zu keiner weiteren Exsudation mehr kam. In einer Reihe von Fällen, in welcher nur wenig rein hämorrhagisches oder nur serös hämorrhagisches Exsudat vorhanden war, gelangte das itbrigens auch ohne Eingriff durch die Application von Carbolglycerin oder Thymol-Naphtholglycerin - welch letzteres ich bevorzuge - zur Resorption. Eigenthümlich aber erscheint hier schon, was wir bei den Exsudaten der hinteren Partie noch viel deutlicher ausgeprägt sehen werden, dass bei Uebergang des hämorrhagischen Exsudates in das eitrige gern eine zapfenförmige Vorstülpung sich bildete, die diesen Fällen eine gewisse Hartnäckigkeit innewohnen liess, indem die vorgewucherte Mucosa oder die die kegelförmigen Hervorragung an ibrer Spitze bekleidende Granulationsknospe sich selten spontan involvirte, sondern meist nur dem chirurgischen Eingriffe der Discision mit nachfolgender Abschabung wich, nicht einer Aetzung oder sonstigen medicamentösen Behandlung.

Wenn auch das Hörvermögen in nicht gerade hohem Maasse beeinträchtigt war, so brauchte es doch eine verhältnissmässig lange Zeit, bis es wieder normal wurde und insbesondere ubberdauerten die subjectiven Geräusche gerne noch lange den ursprünglichen Heilungstermin.

Ein besonderer Einfluss - betreffs Besserung - bei Vornahme der Luftdonche nach Ablauf der acut entzündlichen Erscheinungen konnte im Grossen und Ganzen hier nicht wahrgenommen werden, ebenso wie sich die Geräusche hierdurch in keiner Weise verringern liessen. Dagegen fehlte dieser Gruppe die Auslösung von Erscheinungen des Schwindels, schwererer cerebraler Reizungen und insbesondere Mitaffection der Pars mastoidea, sowie das Auftreten hochfieberiger Temperaturen. Dies gilt aber im Allgemeinen blos für die Fälle, bei welehen das Exsudat lediglich nach vorn vom Proc. brevis circumscript angesammelt war. 
Wesentlich anders gestaltet sich das Symptomenbild der Exsudationen in der hinteren oberen Hälfte, eventuell mit gleichzeitiger Exsudation in die vorderen Partien.

In gleicher Weise gültig wie für die geschilderten Processe der vorderen oberen Partie ist bezïglich des Trommelfellbefundes, dass kein Zeichen einer Exsudation im unteren Paukenraum besteht. Röthung leichteren oder höheren Grades auch intensive zuweilen, ist zwar häufig vorhanden, aber es fehlt eine Vorwölbung völlig. Kaum dass es, in nicht vielen Fällen, nur zu einer leichteren Abflachung kommt. Es handelt sich hier offenbar um eine blos concomitirende Irritation und Hyperämie der eigentlichen Membrana tympani.

Gehen wir nun weiter auf die speciellere klinische Analyse ein, so sehen wir, dass, wieder dem Influenzatypus entsprechend, meist in ausserordentlich rapider Weise, häufig begleitet von sturmischen Allgemeinerscheinungen, unabhängig von anderweitigen Localerkrankungen, eine auf den hinteren oberen Quadranten des Trommelfells beschränkte, oft denselben nur bis zur Hälfte einnehmende exsudative Entziindung sich einstellt. Es entwickelt sich innerhalb eines, seltener mehrerer Tage eine das hintere obere Segment etwa von der Mitte des Hammergriffs beginnende und bis an den Margo hinuiberreichende kugelige oder buckelige, zuweilen blasige Vorwölbung, die nicht selten nach unten zu ziemlich scharf abgegrenzt erscheint; ein mehr diffuses Uebergehen der Grenzen nach unten zu ist hier weniger häufig; kommt es vor, so ist es gemeiniglich das Zeichen, dass eben der Process nicht mehr allein auf den oberen Paukenraum beschränkt ist, da sich dann auch Abflachung der unteren Partien weiter daran schliesst.

Die Farbe dieser Vorwölbung ist entweder dunkelblauroth oder ein schmutziges Violettroth mit Beimischung eines gelblichen Farbentones. Zuweilen befinden sich noch kleinere Ekchymosen in den anstossenden Regionen. Selbstverständlich giebt es anch genug Combinationsformen, in denen der vordere und hintere $\mathrm{Ab}$ schnitt, also der ganze Atticus, gleichzeitig erkrankt erscheinen.

Beinahe constant ist die obere Gehörgangswand in ihrem Uebergange zur hinteren geschwollen und gesenkt und in gar nicht seltenen Fällen weist gleichzeitig oder wenig später auch die hintere obere Wand mehr oder weniger intensive Schwellungsröthe neben Herabtreten derselben auf.

Die Schmerzhaftigkeit ist, meist der Entzündung entsprechend, wenigstens bei hämorrhagischem oder blutig-eitrigem Exsudate, 
weniger bei serösen Ergüssen, eine sehr hochgradige, sehr oft grösser, als bei den auf die vordere Partie beschränkten Processen. Es stellen sich gern irradiirte neuralgische Schmerzen über die ganze Schädelhälfte oder noch weiter über den Hals und Arm hinaus ein. Heftiger klopfender Kopfschmerz in der Schläfe, sowie gerade hinter dem Ohre nach oben $\mathrm{zu}$, ist sehr gewöhnlich dabei. In manchen Fällen Thränenträufeln und Lichtscheu auf dem der erkrankten Ohrseite entsprechenden Auge.

Eigenthümlich ist - für einen Bruchtheil dieser Fälle -, dass, ganz abgesehen von der schnellen oder rapiden Abnahme des Hörvermögens, verbunden mit intensiven, äusserst quälenden Geräuschen, Schwindelerscheinungen auftreten, die sich zuweilen zu directem Dreh- und Sturzschwindel erheben, so dass die Patienten, falls sie tiberhaupt noch im Stande sind, auf zu sein, in ihren willkürlichen Bewegungen sehr beeinträchtigt sind. Dabei äussert sich der Schwindel gewöhnlich in der Weise, dass die Drehung oder Sturzbewegung von der erkrankten Seite aus gegen die gesunde zu erfolgt. Dass sich hierbei nicht selten bohe bis sehr hohe Fiebergrade entwickeln, gleichwie ausgesprochene Zeichen meningitischer Reizung, braucht nicht erst näher erörtert zu werden.

Während das Warzenfortsatzgebiet bei den nur auf einen circumscripten Abschnitt der vorderen oberen Partie beschränkten Entzündungen beinahe durchgehends frei zu bleiben pflegt, kehrt sich hier das Verhältniss um. In beinahe noch höherem Maasse, als dies für die Influenza des unteren und gesammten Paukenabschnittes ja schon längst nachgewiesen war, zeigt sich das Mitergriffensein der Pars mastoidea. Oft treten schon gleich vom ersten Tage ab an den typischen Stellen Druckschmerzhaftigkeit und zugleich spontane Empfindlichkeit ein, oder sie findet sich nach mehrtägiger Dauer des Exsudationsprocesses. Die Percussion giebt in derlei Fällen oft schon verhältnissmässig frühzeitig, abgesehen von dem charakteristischen stechenden Kopfschmerz, ein positives Resultat, indem eine Abdämpfung bei Vergleichung der beiden Seiten nachgewiesen werden kann. Relativ häufig bilden sich die Erscheinungen von Seite des Warzenfortsatzgebietes, auch trotz der Perforation, nicht mehr zurück; es kommt in rascher Entwicklung der weiteren Symptome zur Empyembildung in den Zellen oder in weiter sich hinaus ziehenden Fällen zur Granulationsbildung nebst cariöser Arrosion. Und dass die Sache auch ganz gut noch weiter zu schweren intrameningealen Erscheinungen führen kann, ist, wie wir aus unserem 
VIII. Falle sehen, leicht möglich. Uebrigens dürfen wir nicht ausser Acht lassen, dass bei dem sehr frübzeitigen Auftreten von Schmerzen in der Mastoidgegend eine primäre Mastoiditis vor. handen sein kann, wie wir ihr an einer anderen Stelle begegnen werden und es dürfte wobl fuir einen Theil der Fälle wabrscheinlich sein, dass eben die Pars mastoidea wirklich die primär erkrankte Partie war.

Es bandelt sich also bei einer grossen Anzahl dieser Processe der hinteren oberen Partie wohl nicht blos um eine Exsudatansammlnng in den hinteren Partien des Recessus allein, sondern um eine gleichzeitige Erkrankung des hinteren Recessus und der Pars mastoidea, wenigstens des Aditus ad antrum und des Antrum selbst. Dass es natiurlich, bestimmte anatomische, nicht normale Verbältnisse vorausgesetzt, zuweilen zu wirklich blos auf die hintere obere Partie des Trommelfells allein beschränkten Exsudaten kommen kann, soll damit nicht in Abrede gestellt werden, aber immerhin werden solche blos abgekapselte Exsudate zu den Ausnahmen gehören.

Das geht - wie wir es ja an der Hand der Obductionsbefunde und der Operationsfälle wieder sehen -, auch aus dem ferneren Verlaufe der Medien selbst hervor.

Erfolgt die Spontanruptur der Membran am 2.-4. Tage, bei den Entzündungen der unteren Hälfte (Influenza) tritt sie häufiger schon am 1.-2. Tage ein - so ist die Perforationsstelle nie in der unteren Partie, sondern immer hinten oben, zuweilen sogar hart am Limbus, sie rückt weitestens bis an die Hälfte des hinteren Segmentes berunter, aber tiefer nicht. Und, hat man die Discision von oben bis unten gemacht, so passirt es, dass trotzdem die untere ausgiebige Schnittlinie bäldestens verharscht; der Eiter sickert ans der oberen Oeffnung in unverhältnissmässig: reichlicher Menge nach Uebergang des hämorrhagischen Secretes ins Eitrige. Eigenthitmlich ist dann auch fernerhin, dass die Sehmerzhaftigkeit im Ohre selbst sich trotz des Abflusses und trotz erneuter Tieferlegung des Abzugskanales sich nicht verliert, sondern in Uebereinstimmung mit der Empfindlichkeit der Warzenfortsatzregion fortdauert, in oft sehr rasch weehselnder Weise.

Ist schon so die Localisation der Perforationsstelle eine suspecte, so begründet sich der Verdacht noch weiter durch die eigenthümliche Granulationstendenz derselben: es treten sehr gerne die ja schon längst bekannten zapfenförmigen Vortreibungen auf, kleine Granulationskegel, aus deren feiner Spitze ein Eitertröpfehen 
hervorsickert, das sich nach dem Abwischen, obne jede Luftverdichtung vom Nasenrachenraume her, sofort unter dem Blicke des Beschauers wieder bildet.

Uebrigens bemerkt man gerade hier häufig, wenn die Luftdouche in späteren Zeitstadien angewandt wird, dass durch diese beinahe gar kein Einfluss auf das angesammelte Seeret ausgeiibt wird: es giebt selten Perforationsgeräusch, und es drängt sich auch nicht neuer Eiter zur Lücke heraus. Der Luftstrom wölbt wohl die unten liegenden Partien vor, lässt aber die oberen scheinbar unberührt.

Ganz prägnante Symptome bietet dann weiter häufig während des ganzen Verlaufes das Verhalten der Gehörgangsveränderungen dar. Ist schon gleich von Anfang an die Uebergangspartie hinten oben lebhaft geröthet und oft auch geschwollen, so bildet sich, zuweilen ziemlich raseh, eine exquisite Senkung der ganzen hinteren Gehörgangswand, die sich dann noch auf die hintere Hälfte der oberen Wandung fortsetzt. Es resultirt daraus in manchen Fällen eine hochgradige, beinahe schlituformige Verengerung des Meatuslumens. Diese Senkung verliert sich nicht mehr in den allermeisten Fällen bis zur operativen Eröffnung der Warzenhöhle und des Recessus.

Es ist ja bekanntlich dieses für die Diagnose der Warzenfortsatzcomplicationen ausserordentlich wichtige, zu den allerverlässigsten Symptomen gehörige Merkmal sehon längst hervorgehoben worden, zuerst von Schwartze. Ganz entsprechend diesen Gehörgangsverhältnissen kommt es bei pneumatischen und mit dünner Corticalis versehenen Warzenfortsätzen anch zu einer objectiv sich durch Schwellung und Röthung kennzeichnenden Mitbetheiligung der Periost- und Weichtheillager. Bei dicker Corticalis und bei sklerotischen Warzenfortsätzen aber fehlt beinahe durchgehends jedes äusserlich mit dem Ange wahrnehmbare Symptom. Dass speciell bei der letzteren Gruppe verhältnissmässig häufiger intracranielle Complicationen zur Beobachtung gelangten, ist bei diesen anatomischen Verhältnissen nicht zu verwundern, so wenig als wenn sich bei den stark pneumatischen Warzenfortsätzen eine Senkung nach unten zuweilen herausbildet.

Weiter den Verlauf in klinischer oder operativer Hinsicht zu schildern, dürfte überflussig erscheinen, da er sich von da ab mit den aus anderen Ursachen hervorgegangenen Warzenfortsatzerkrankungen vollkommen deckt. Höchstens wäre noch das zu bemerken, dass sich beinahe nur in ganz fribzeitig zur Operation 
gelangten Fällen, also etwa in der 3. oder 4 . Woche nach Beginn der Ohrerscheinungen, blos Eiteransammlung in den Höhlen des Processus vorfand. Wenn die Fälle später zur Operation kamen, waren fast durehgehends schon cariöse Arrosionen, zaweilen schon relativ weit gediehene vorhanden; tubrigens kam das auch sogar innerhalb der vorgenannten Gruppe zur Beobachtung.

Die Heilung der operirten Fälle vollzog sich in einem Zeitraume von 5-6 Wochen und $2-4$ Monaten. Spontaninvolutionen kamen beinahe nur in solchen Fällen zur Beobachtung, in denen es sich um gewissermaassen abgekapselte Exsudate gehandelt batte; wenigstens entzogen sich eventuell andersgeartete nach Eintritt der Besserung durch Ausbleiben einer genaueren Controle.

Als nicht ganz nebensächlich möchte noch bemerkt sein, dass das Hörvermögen oft sich nach Abfluss des Eiters verhältnissmässig rasch besserte, dass aber subjective Geräusche gewöhnlich noch lange anhielten und die Heilung überdauerten.

Eine besondere Würdigung dürfte in klinischer Beziehung noch unser VIII. Fall verdienen, in welchem es im Verlaufe einer an eine Pneumonie (ex influenza) sich anschliessenden eitrigen acuten Media zur Sinusthrombose kam. Nach 2-3 tägiger Dauer der Ohrschmerzen stellte sich eine gewöbnliche Otitis purulenta ein, die aber schon, ehe es noch zum Durchbruch (spontan) kam, mit Schmerzhaftigkeit in der Warzenfortsatzgegend vergesellschaftet war, die sich äusserlich wahrnehmbar gemacht hatte, neben der Schmerzhaftigkeit durch leichte Röthung und Schwellung. Statt der bisher geäusserten lebhaften Schmerzempfindungen zeigt sich bei hoher Temperatur und verlangsamtem Pulse eine Indolenz, die in einen somnolenten Zustand übergeht.

Objectiv sieht man eine starke Senkung der hinteren Wand bis zur beinahe schlitzförmigen Verengerung des Meatus und mit vieler Mühe - wegen der Senkung der Wand - eine mit Granulationen besetzte buckelig-kegelige Erhabenheit - im hinteren oberen Segmente; Eingehen mit der Sonde in die oben gelegene Lïcke ruft Sturzbewegung hervor. Warzenfortsatz kaum geschwollen, aber auf Druck und spontan sehr empfindlich bei percutorischer Abdämpfung.

Da die Operation zunächst noch nicht gestattet wird, so wird Dilatation der Lücke nebst Abschabung der Granulationen vorgenommen.

Hierauf temporäre Besserung unter Nachlass der Schmerzen und Vermehrung der Secretion. Nach 5 Tagen rapide Verschlim- 
merung des Zustandes unter Schüttelfrost, Temperatur von 39 bis 40, verlangsamtem Pulse, hochgradige comaähnliche Indolenz, Irrereden. Warzenfortsatzregion nicht mehr geschwollen, aber noch empfindlicher, wie fruber; sehr empfindliche Stelle kurz uiber der Linea temporalis. Druckschmerzhaftigkeit im Warzenfortsatzwinkel, hinunter längs des Sternocleido, bei leicht vermehrter Resistenz der Jugularisgegend. Keine Schwellung in der Temporofrontal- oder Occipitalgegend, kein Brechen. Ophthalmoskopisch: Stauungspapille beiderseits, besonders links.

Es musste also die klinische, schon früher als wahrscheinlich angenommene Diagnose jetzt als sicher gelten: Empyem des Processus mit intracranieller Complication, speciell Thrombose des benachbarten Sinus.

Da von vornherein angenommen worden war, dass es nicht blos bei einer Eröffnung des Warzenfortsatzes seine Bewenden haben werde, so wurde die Schnittführung a priori in einer den Eventualitäten entsprechenden Weise vorgenommen.

Die Eröffnung des Warzenfortsatzes ergab zunächst thatsächlich ein Empyem des Antrum und der Spitzenzelle.

Man hätte also bei diesem positiven Befunde sich eventuell beruhigen und die Operation abschliessen können, aber bei der Lage der Allgemeinerscheinungen musste das doch bedenklich erscheinen, insbesondere da offenbar schon Resorption septischen Materiales stattgefunden baben musste und hier eventuell jeder Tag kostbar werden konnte. Bei weiterem Nachsuchen ergab sich auch wirklich, dass in den hinteren oberen Winkel der ausgeweiteten Warzenfortsatzhöhle ein Strang hereinreichte, der bei der näheren Besichtigung als eine thrombosirte Knochenvene sich erwies. Das musste genügen, um ein weiteres sofortiges Vorgehen zu rechtfertigen. Es wurde zuerst entlang dieses Leitungskanals die hintere Wand des Processus, die sich so wie so blos mehr 2-3 Mm. dick zeigte, langsam weggenommen, bis Dura und Sinus auf tiber $2 \mathrm{Cm}$. freigelegt war.

Die Dura nirgends missfarbig, nicht mit Granulationen bedeckt, blos höchstgradig hyperämisch, beinahe cyanotisch; die venösen Gefässe ausserordentlich prall gefullt. Der Sinus erwies deutlich eine Thrombosirung, indem er in der ganzen freigelegten Strecke als derber, pulsloser, an einer mittleren Partie leicht dellig eingesunkener Strang sich repräsentirte.

Die vorsichtshalber zur Sicherung der Diagnose vorgenommene Probepunction förderte blutig-eitrige Flüssigkeit zu Tage. 
Dementsprechend musste die Incision der Sinuswand gemacht werden und es ergab sich in der Folge, dass die Thrombose noch nicht völlig freigelegt war, so dass noch weitere Wegnahme des Knochens erfolgen musste.

Da die der centralen puriform erweichten Partie des Thrombus benachbarten Theile desselben doch sich etwas suspect ansahen, so wurden sie vorsichtig entfernt, ohne dass Blutung aufgetreten wäre. Der Sinus war nun in einer Länge von $2,2 \mathrm{Cm}$. eröffnet; von einer Excision der intermedialen Partie wurde Abstand genommen.

Ohne weitere mechanische oder chemische Irritation wurde einfach tamponirt.

Auch die Jugularis wurde einstweilen noch nicht aufgesucht. Es wäre dies schon wegen der relativ langen Dauer der Operation, sie hatte bisher $11 / 4$ Stunde gedauert, und wegen des wirklich schlechten Zustandes des Patienten, der schon wiederholt Kampherinjectionen batte erhalten müssen, nicht mehr rathsam und auch nicht mebr gut ausführbar gewesen. Und dann waren die diesbeztiglichen Symptome keineswegs so prägnant, dass man diesen Eingriff, einen gewiss nicht gleichgültigen, absolut hätte vornehmen müssen - gleichzeitig, d. h. eigentlich vorausgehend. Uebrigens ist ja bekanntermaassen die Frage der gleichzeitigen Unterbindung der Jugnlaris bei Sinusthrombose noch eine offene, deren officielle Berechtigung noch durchaus nicht überall anerkannt wird und werden kann. Die Resultate, welche Langenbuch in jüngster Zeit in dieser Beziehung verzeichnet bat, lauten in keiner Weise ermunternd. Jedenfalls glaube ich keinen Fehler begangen $\mathbf{z u}$ baben durch die Unterlassung der Jugularisligatur.

Dafür spricht auch, was das Wichtigste ist, der weitere, so gar unverhältnissmässig günstige Verlauf des Falles, indem direct nach Ausführung des Eingriffs kein Schüttelfrost mehr auftrat, sich die Allgemeinerscheinungen in raschem Tempo zurtickbildeten, die Temperatur nach sehr geringen Schwankungen eine normale blieb, die Erscheinungen von Seiten des Augenhintergrundes verschwunden waren. Ebenso hob sich das Allgemeinbefinden des sehr heruntergekommenen Individuums verhältnissmässig sehr schnell.

In der 9. Woche war der Substanzverlust der hinteren Schädelpartie annähernd übernarbt, nachdem die Secretion aus dem Meatus schon am 10. Tage nach der Operation aufgehört hatte.

Es gebt ans der Verfolgung dieses Falles wieder von Neuem 
klar hervor, dass wir bei irgend einigermaassen ausgesprochenem Hervortreten von Symptomen, die auf eine intracranielle Complication, speciell auf eine Verlegung der grossen venösen, dem erkrankten Ohre direct benachbarten Blutbahnen, eventuell mit schon geschehener Weiterverschleppung septischer und pyogener Keime hindeuten, unter keinen Umständen zögern dürfen mit der breiten Freilegung der ganzen in Frage kommenden Region. Die Eröffnung der Warzenzellen allein ist, auch wenn sic wie hier, ein vollständig positives Resultat hat, doch blos als ein zur Zeit palliativer und vorbereitender Eingriff zu erachten, da dann schliesslich doch noch die weitere Wegnahme der die Sinusgegend deckenden Knochenpartien erfolgen muss und das dann vielleicht zu einer Zeit, in der die Proguose sich wesentlich ungünstiger gestalten wird vermöge des bereits weiter gediehenen Krankheitsprocesses.

Wäre wenigstens in unserem Falle die sofort folgende Freilegung und objective Untersuchung unterblieben, so hätte entweder ganz kurze Zeit nach Vornahme der ersten Operation die Fortsetzung derselben folgen müissen - und unter solchen Umständen ist die verhältnissmässig frühzeitig wiederholt nothwendige Narkose schon nicht mehr als ganz gleichgilltig anzusehen - oder der Patient wäre mit grösster Wahrscheinlichkeit der beginnenden septischen Infection erlegen. Bei dem thatsächlichen Auffinden eines von oben in die eiterbaltige Knochenhöhle bereinreichenden obturirten venösen, also mit den oberen meningealen Partien zweifellos communicirenden Gefässes wäre es ein Fehler gewesen, dieser Bahn nicht sofort zu folgen. Aber selbst wenn sich nach der wenigstens zur Orientirung nöthigen geringmöglichsten Freilegung gar keine weiteren Kennzeichen hätten finden lassen, wäre der eventuell nach einer Probepunction abzuschliessende Explorativeingriff als ein den gegebenen Verhältnissen nicht nur entsprechender, sondern beinahe nothwendiger zurechtfertigen gewesen und das um so eher, als die einfache Freilegung und eventuell die Punction Eingriffe sind, die an und für sich keinerlei Folgen nach sich ziehen, wie ja das durch eine Reihe von Beobachtungen zur Genüge erhärtet ist.

Eine eigentliche Excision der verlegten Sinuspartie schien mir nach sorgfältiger $\mathrm{Ab}$ - und Ausräumung der verdächtigen Partien nicht absolut nothwendig, obschon die Möglichkeit einer in die Wandungen und ihre directe Nachbarschaft eventuell erfolgten Infiltrationsinfection, die dann wieder Veranlassung geben konnte 
zu einem Weiterkriechen jenseits der Enden, nicht ausgeschlossen war. Allein das hätte schliesslich trotz der Excision der primär inficirt gewesenen Partien durch bereits nach der Peripherie hin eingeleitete Fortschleppung geschehen können. Jedenfalls war das Postulat der möglichst frühzeitigen und gründlichen Schadlosmachung des Herdes, von dem aus die septicämische Infection der grössten Wahrscheinlichkeit nach allein herstammen musste, erfullt worden.

Betreffs der eventuell noch in Frage kommenden gleichzeitigen Unterbindung der Jugularis habe ich schon oben das Hauptsächlichste besprochen: Vielleicht dürften wir noeh darauf hinweisen, dass es sich hier möglicher Weise um eine der von $\mathrm{Zaufal}$ seinerzeit sehon näher präcisirten transitorischen Thrombosen handelte. Jedenfalls war hier noch keine wirkliche Verlegung des Jugularisgebietes vorhanden, sondern es könnten höchstens die ersten Anfänge dazu gegeben gewesen sein.

$$
\text { Pathologisch-anatomische Deductionen. }
$$

Treten wir, ehe wir an die eigentliche Registrirung der anatomischen Daten gehen, kurz zuerst der Frage der Aetiologie näher, d. h. ob diese Ohrerkrankungen thatsäcblich auf Influenzainfection beruhten, so können wir dies für $38 \mathrm{der}$ vorliegenden 64 Fälle annähernd bejahen, indem sich entweder in dem durch die Paracentese gewonnenen oder bei der Spontanperforation entleerten Secrets die als Infuenzamikroorganismen beschriebenen specifischen Bacillen nachweisen liessen.

In 18 Fällen von rein hämorrhagischem oder bämorrhagischserösem Exsudat waren sie der Hauptsache nach überwiegend vorhanden; in allen ubrigen hämorragisch-eitrigen oder rein eitrigen Entzilndungsproducten dagegen fand sich der specifische Mikroorganismus stark gemischt mit dem Diplococcus pneumoniae oder mit dem Streptococcus pyogenes.

Bei den mit Warzenfortsatzcomplicationen verbundenen Fällen waren immer nur Mischformen zu beobachten, es überwogen da in 4 Fällen die Pneumoniediplokokken, in 9 die Streptokokken.

Was nun zunächst die Exsudatansammlungen, beschränkt auf die vordere Partie des Recessus allein, anbelangt, so vermag ich hier keine anatomischen Daten zu geben, da mir ein solcher Fall nicht zur Obduction gelangte.

Dagegen sehen wir an den obducirten Fällen, insbesondere deren erstem, dass sich hauptsächlich der hintere Theil der Pars 
epitympanica erkrankt zeigte. Während im unteren Paukenraum keine oder wenigstens keine nennenswerthen Veränderungen sich vorfanden, bemerken wir hier Exsudatbildung von der Hammerambosnische $a b$ in den Prussak'schen Raume, der hinteren Trommelfelltasche, dann weiter den hinteren oberen Raum einnehmend und in den Aditus ad antrum und das Antrum selbst vordringend.

Im zweiten, mit vorwiegend serösem Exsudat einhergehenden Falle sind beinahe die gleichen Partien erkrankt, nur dass hier das Exsudat noch nicht auf die eigentliche Pars mastoidea tibergegriffen hatte.

Besonders eigenthümlich muss uns erscheinen das Verhalten der hinteren Trommelfelltasche; sie war in diesen beiden Fällen durch membranöse Adhäsionen nach unten zu ganz oder wenigstens nahezu ganz abgeschlossen, so dass also, nattixlich blos für di ese Fälle genommen, ein Exsudaterguss sich als circumscripte Vorwölbung der hinteren oberen Partie zeigen konnte. Unter normalen Verhältnissen kann ja ein Flüssigkeitserguss unter keinen Umständen auf die Tasche allein beschränkt bleiben, da ja sie bekanntlich beinahe constant nach unten zu offen zu sein pllegt. Während in dem ersten der Fälle diese Pseudomembran oder dieses Pseudoligament sammt ihren Appendices eine sehr derbe und feste Consistenz, nach Art eines narbigen Bindegewebestranges hatte, waren es in dem zweiten entschieden viel jüngeren Datums; hier handelte es sich um offenbar entzündliche Adhäsionen, die sich vielleicht mehr oder weniger kurze Zeit vor Eintritt der eigentlichen Influenzaattacke gebildet hatten, an einem durch tubare Einsenkung stark retrahirten Trommelfelle - wenigstens wies das andere $\mathrm{Ohr}$ diese Veränderungen auf und es kann wohl mit einer gewissen Berechtigung angenommen werden, dass anch dieses erkrankte Ohr denselben Einflüssen ausgesetat gewesen sei, und dass durch einen vorausgegangenen Tubo-tympanalen subacuten Entzïndungsprocess eine Verlöthung erfolgt sei.

$\mathrm{Ob}$ in dem anderen (ersten) Falle die Abschlussmembran als Entzündungsproduct älterer oder vielleicht schon alter Provenienz aufzufassen sei oder aber als eine von Haus aus gegebene anatomische Verbildung der Tasche, lässt sich bier nicht entscheiden mit Sicherheit. Wahrscheinlich dürte es sich jedoch auch hier um Residuen abgelaufener entziundlicher Processe handeln, worauf insbesondere anch noch weiter die pathologische Spangenbildung innerhalb des abgeschlossenen Taschenraumes hinweisen muss. Die Ursache dieser Pseudoligamentbildung dürfte wohl 
in einer früheren acuten exsudativen Entzündung des unteren Raumes zu suchen sein, der sich wohl auf die hintere Tasche erstreckte und nach Abheilung in der unteren Partie noch längere Zeit in der oberen einen Reizzustand veranlasste.

Die Luicke dagegen, die wir in dem dem Paukenraume zugekehrten Blatte der Tasche nach oben zn finden, ist wohl schwerlich anders zu erklären als durch präformirte Spaltbildung; die Ränder dieses Schlitzes sind in der nämlichen Weise scharf abgeschlossen, wie wir sie ja bäufig bei den präformirten Communicationen innerhalb der die Hohlräume des oberen Stockwerkes bildenden Taschen und Falten sehen können. Auch ihre ovale Form fubrt darauf hin.

Während es in dem ersten Falle zu einer umschriebenen Vorbauchung der gesammten hinteren oberen Trommelfellpartie kam, haben wir im zweiten ein blasenartiges Abgehobensein der Cutisschicht allein, die dadurch zu Stande kam, dass vermöge eines Einrisses in die entzindlich erweichte Propria-Mucosa ein Eindringen der Exsudatmassen in die nach unten abgeschlossene Tasche erfolgen konnte. So erklärt sich ungezwungen die herniöse Vorstulpung der Cutislage hinten oben.

Es sind nun diese beiden anatomischen Befunde von ausserordentlichem Interesse, weil sie uns zeigen, wie unter gewissen Verhältnissen circumscripte Exsudatansammlungen sich am Trommelfell bemerkbar machen können.

Im ersten Falle sehen wir das Eindringen des Secretes aus dem hinteren oberen Theile des Paukenraumes durch eine präformirte Lucke in die nach unten durch pathologische Ligamente abgeschlossene Tasche; im zweiten finden wir das Exsudat, von oben her communicirend mit einem Theil der Hohlräume des Processus, sich ergiessend durch einen Riss (jüngsten Datums) der zwei Trommelfelllamellen in die nach unten durch relativ frisehe Verlöthungen abgesehlossene Tasche, so dass eine circumscripte herniöse Vorstïlpung der Cutislage im hinteren oberen Segmente zu Stande kommt.

Beiden Fällen gemeinsam ist, dass sich der hintere obere Theil des Recessus und stellenweise auch noch die vorderen Partien des Recessus mit Exsudat erfüllt erwiesen.

Bacteriologisch war auch in diesen beiden Fällen ein $\mathrm{Zum}$ sammenhang mit Influenza zu constatiren.

Auf jeden Fall haben wir es hier mit selteneren Ausnahmefällen zu thun, in denen es durch voransgegangene Entzündungs- 
processe zu Verlöthungen im Gebiet der hinteren Tasche gekommen ist. In einem dritten Obductionsfalle, in welchem während des Lebens ebenfalls eine Vorbauchung im hinteren oberen Segmente und in der vorderen oberen Hälfte vorhanden gewesen war, fehite jede Verlöthnng im Taschenrayon.

Wenn wir also auch für einen wahrscheinlich sehr kleinen Bruchtbeil von Exsudatansammlung der hinteren oberen Partie annehmen können, dass ein Flüssigkeitserguss in der abgeschlossenen hinteren Tasche als circumscripte Vorwölbung an der gegebenen Stelle sich nach aussen repräsentiren könne, so dürfte doch der Meinung Escat's ${ }^{1}$, dass es sich bei den meisten circumscript erscheinenden Vorwölbungen der genannten Partie um Exsudatansammlungen in die durch Psendomembranen abgeschlossene hintere Trölt'sche Tasche handle, schwerlich in diesem Umfange beizupflichten sein. Escat hat diese Vermuthung blos auf Grund klinischer Beobachtungen (bei acuten Mittelohrentzündungen) ausgesprochen.

Kehren wir nun noch kurz zu einigen Allgemeinbetrachtungen zurïck, so können wir an der Hand der anatomischen und klinischen Beobachtungen der Meinung Ausdruck verleihen, dass es im Verlaufe der acuten Influenzainfection, gleichwie dies ja schon für andere acute Infectionen und auch schon für Influenza in allgemeinerer Beziehung festgestellt worden ist, nicht zu selten zu einer acuten Exsudation in die sämmtlichen Abschnitte des oberen Paukenraumes unter gleichzeitiger Miterkrankung der Warzenfortsatzregion kommen kann. Selbstverständlich wird es ausserdem eine grosse Anzahl von Fällen geben, in welchen das gesammte Höhlensystem des Mittelohres, die unteren Partien mit einbegriffen, gleichzeitig oder kurz nacheinander afficirt wird.

In den angezogenen Fällen aber beschränkte sich die Erkrankung auf das obere Stockwerk der Trommelhöhle, entweder auf die vordere Hälfte allein oder aber, häufiger noch, auf die hintere Hälfte; dabei ist ein Zusammenfliessen, vermöge der ja oft präformirten Spaltbildungen, wohl durchaus nicht zu selten, so dass eben schliesslich der ganze obere Paukenraum erkrankt erscheint.

Auf jeden Fall bekommen wir, speciell durch die erste der Obductionen, einen klaren Einblick bezüglich der unter Umständen geradezu foudroyanten klinischen Erscheinungen, die sich bei den Exsudatansammlungen, auf den oberen Raum allein, speciell

1) Bulletins et mémoires de la société française d'Otologie etc. Tome XI. p. 367 . 
die hintere Partie desselben beschränkt, verbältnissmässig nicht so selten gezeigt haben.

Zunächst lässt sich die gewöhnlich sehr hochgradige Schwerhörigkeit leicht erklären dadurch, dass das Exsudat grösstentheils solche Partien auskleidet und erfullt, die fur die acustische Function von einschneidendster Bedeutung sind. Es muss nothwendiger Weise durch ein so localisirtes Exsudat die Bewegungstähigkeit des gesammten Gehörknöchelchenapparates schwer beeinträchtigt werden, insbesondere wenn das Exsudat noch gegen das ovale Fenster zu drückt und gegen die Fenstermembran selbst, unter Lockerung der Platte und Imbibition der Membran vordringt.

Hierin haben wir wohl anch grösstentheils die Ursache der schweren Schwindelerscheinungen zu suchen, die in einem Theile der Fälle aufgetreten waren, um dann bei der durch die Paracentese erfolgten Entlastung, resp. vermöge der durch dieselbe hervorgerufenen Verminderung des intralabyrinthären und intracraniellen Druckes zurickzugehen. Als Paradigma könnte hier der Fall V gelten, in welchem sofort nach Vornahme der Paracentese die allarmirenden Erscheinungen des rechtsdrehenden Sehwindels, des Blepharospasmus, ders Supraorbitalneuralgie, der Cephalalgie u. s. w. verschwanden.

Auch das verhältnissmässig oft über sehr lange Zeit sich hinziehende, über die eigentliche Vernarbung hinaus dauernde Anhalten der subjectiven Geräusche lässt sich wohl, zum Theil wenigstens, aus der Localisation der Secretansammlung erklären, da die absolute Rückbildung ad normam hier viel längere Zeit in Anspruch nimmt als bei Exsudaten der unteren Trommelhöhlenhälfte.

Auch die infolge der Entzündung hier sich nicht so sehr schwer bildenden Adhäsivprocesse können durch die producirten Neomembranen oder Pseudoligamente ausserordentlich wirksam sein und vielleicht auch in einzelnen Fällen dauernd bleiben, sowohl beztiglich der Function des Hörens als der subjectiven Geräusche. Insbesondere werden die einmal gesetzten Veränderungen in der Fensterregion, denen sich später bindegewebige Consolidation mit abnormer Fixation der Steigbiigelplatte im Fenster zugesellen kann, sich als einer dauernden Riuckbildung unfähig erweisen können; die Folge hieraus ergiebt sich von selbst.

Dass auch nach relativ günstigem Ablaufen solcher Entzïndungen bei dem eventuellen Neuauftreten entzündlicher Processe gerade für die Bildung von circumscripten Exsudatansammlungen 
in den Hohlräumen der oberen Paukenetage günstige Bedingungen geschaffen werden können, darauf möge nur hingewiesen sein.

Was nun endlich die von Seite der Pars mastoidea und eventuell ihrer Nachbarschaft vorliegenden Erscheinungen anbelangt, so erklären sich diese ohne Weiteres durch die einfache Thatsache des Uebergreifens des exsudativen Processes auf die zelligen Hohlräume und ich glaube, wir dürften auch hier nicht zu weit fehl gehen, wenn wir annehmen, dass in einem grossen Bruchtheil aller der Fälle, die mit prononcirter Exsudatbildung der hinteren Hälfte des Processus einhergegangen sind dem Symptomenbilde nach, eine gleichzeitige oder wenigstens sehr kurz nach der Recessusaffection sich einstellende Erkrankung des Warzenhöhlensystems, mithin, eine Affection des gesammten oder beinahe ganzen Paukenraumes mit Ausschluss der unteren Partien vorliege. 